\title{
Marijuana in the US -Science, Ideological Dialectics, and predicted flows from Latin America
}

\author{
Ki Hoon Jun* \\ Graduate School Latin American Studies, Hankuk University of Foreign Studies, South Korea
}

Received: May 20, 2018; Published: May 31, 2018

*Corresponding author: Ki-Hoon Jun, Graduate School Latin American Studies, Hankuk University of Foreign Studies, South Korea

\section{Abstract}

Counter-intuititvely, it is socio-historical, geographic traits, and natural conditions which led to marijuana's stigmization as drug. Besides, its stigmization in U.S. is rather related with racialorign of its introduction; it was first brought by black slaves and Mexican refugees fleeing from Mexico Revolution in 1910. Despite previous prevalence of its consumption over tobacco, since 1920s the white's racist fear and ant sentiments led to its prohibition. However, since late-2000s scientists began revealing that marijuana's defects had been hitherto exaggerated and that its harm is even less than that of alcohol-drink. Besides, the racist origin of marijuana prohibition lately came into light, suppressing any antimarijuana stance as a strong ideological tool. As a result, by 2016 more than a half of Americans consume or have consumed marijuana. And anti-racist appeal against marijuana-restriction is serving as a strong ideological and moraalistic apparatus to suppress any further warning against marijuana-overdose or over-diffusion. But while it's soaring demand is hardly met by domestic production, which is feasible only in California for natural condition. Then the majority should come from Latin American imports.

That raises another question: how would its flow pattern be? Expectedly, the major flow of Latin American import of U.S. marijuana should start from Colombia, who has not only legalized but also set marijuana as a core item for national industrialization from 2017. But its government cannot control the custom procedure of Central American countries and Mexico, by where its products have to pass to arrive at U.S. market, the main export target. Then, they need mediators or retailers. It is here when drug cartels of Mexico, located between Colombia and U.S., can make indirect influence. They will not engage themselves into the business for its low profitability. However, from 1980s when they traded with Colombia cartels, they have secured their covert path. Besides, some of numerous politicians/businessmen who collude with those drug-cartels might seek marijuana's monopolistic retailing, by acquiring/bidding for access to drug cartels' own secret-roads for drugtrafficking, which is more efficient than using low-developed infrastructure of Mexico with very-slow administrative procedures.

But if this occurs, for the part of U.S. authority, they have to bear more burden to struggle throughout Central America. Now they have to expand their vigilance from only drug-cartels, to also their colluding politicians'/businessmen's activities, perhaps covering the majority of Mexican territory. Although marijuana's defect is much less than other drugs' one, still its over-diffusion can affect the society; furthermore, if it is imported through Mexico in monopoly or smuggling, then other problems can occur.

Keywords: Marijuana; Legalization; Racial Origin; Ideological Dialectics; Monopoly; Secret Tunnel

\section{Introduction}

Since mid-2000s, following the sharp increase of studies on marijuana/cannabis' real effects, U.S. society is now tolerant with marijuana-smoking. And in various respects, more recently the loosening of social restraint against marijuana-consumption is becoming more apparent and visible. By now, furthermore, the American political conservatism's nature seems to be more distant from whether to regulate marijuana-consumption, in two respects: (1) since 2010s, the self-restraint and indulgence-avoidance became no longer the core value in American conservatism, replaced by emphasis on economic protectionism and American exceptional ism [1]. In fact, the restraint is never of social values for the white working class [2], which is the main basis for current Trump government. With accumulating scientific findings showing marijuana's lower harmfulness and political phase moving away from the issue of drug/substance use, currently the social barriers to marijuana-consumption in U.S. is rapidly weakening. However, due to natural condition, only California in the U.S. can produce massive cannabis/marijuana and the increasing demand would be supplied from outside that is, Latin America.

In fact, while U.S. drug problems largely involves import/smuggling from Latin America, the Latin American governments' will and ability to cooperate for U.S.'s drug problem is also varied by 
their own socio-political circumstances. Then, turning into Latin America's status, there are two recent events which deserve the special attention; one is, Colombia's national-industrialization of marijuana/cannabis cultivation; the other is, Mexico's legal regulation of cannabis/marijuana, along with its drug-cartels' past and present social impacts and their roles in drug-transport. Also there are other Latin America's own socio-political factors which affect cannabis/marijuana's circulation to U.S. Summing up those multi-faceted pictures, the present paper deals with the following subjects. First, following clarification of actual effects/defects and nature of marijuana/cannabis in respect to those of other substances, I deal with changing social recognition of marijuana consumption in U.S.'s socio-historical context.

Then I focus on more recent social-viewpoints on marijuana-consumption in U.S., to confirm that U.S. is losing many apparatuses to control prospective trend of over-consumption of marijuana, and that its soaring demand cannot be met by domestic production. While this means that Latin America, especially Mexico and Colombia, will have substantial roles in marijuana-circulation into U.S., I will finally address predicted path of marijuana/cannabis circulation into U.S., and expected burdens and tasks for the part of U.S. authority. Besides, unlike typical journal article, I beg readers' understanding that this paper cannot follow the typical structure of journal article consisted of literature review, methodological, findings, etc. Its main reason is that, I am not dealing with a single specific subject of marijuana/cannabis, but rather drawing a big picture about U.S. marijuana in the close future, by summing up distinct facets on marijuana issues. Due to such nature of the present study, this paper is organized by each distinct facets on marijuana, rather than the typical chapter of literature review, research design, findings, etc. Given that, the subsequent chapter begins with marijuana/cannabis's distinguished nature from other drugs mostly known.

\section{How Marijuana Differs From Other Drugs in Danger, Addictiveness, and Lethality}

To begin to distinguish marijuana from other drugs, first I shall list the most commonly known drugs to us. They include the follows: opium (and poppy as its plant), cocaine, morphine, heroin, methadone, and fentanyl.

And in my View, there are three Criteria for Defining 'illegal Drug', as Follows:

a) Impact on human body and critical organs (e.g. brain and cardiorespiratory organs like heart, lung, etc.)

b) Individual mental defects and its social loss - for example, violence, failure to self-control, and dangerous behaviors led by delusions.

c) Addictiveness; in other words, hardship to escape from dosage by one's will

\section{With Those Three Criteria, I will Compare the Hazard of the Listed Drugs}

a) Heroine and Fentanyl: they can lead to death even only by a single dosage [3]. Fentanyl, while sometimes used for med- ical purpose of pain-killing, it is more often detrimental to our body, blocking nerve signals' flow; this could in turn cause cease of respiration and even death [4]. When it comes to the heroine, its single dosage rarely causes death, because the drug-taker is likely to fall into sweet-illusion and sleeping before over-taking; however, even its single dosage is followed by serious and permanent withdrawal-effect; for example, constant repletion of fierce-pain whenever stopping its consumption [5].

b) Cocaine: its long-term over-taking can also seriously harm, though to the lesser degree than heroine, like sleeping disorder, delusion, and antisocial personality disorder [6], and its withdrawal effect can reach to even the committing-suicide and chronic anxiety [7].

So allowing those drugs can be hardly justified. They damage not only a person's life, physical and mental health, but socially harms even more than the suicide. Therefore, there are enough grounds to outlaw them. On the contrary, however, the same does not apply to marijuana and LSD. Their defects are not serious as the aforementioned three. But besides, the degree of their defects also differs. Unlike marijuana, the LSD does cause delusions [8]; while this sometimes can help someone's creativity by allowing thinking differently, and while it can be used also used for psychiatric purpose, it is still dangerous with risk of causing any abnormal behaviors. Turning to marijuana, while it also causes delusion, its delusion differs from that of LSD in that it is not deviated from his/her real experiences; that is, those delusions are not pure imagination, but rather like confusing the past and the present, or one-sided sensory symptoms. For example, after consuming marijuana one can feel sweeter with the music or beverage he/she used to take everyday [9]. Besides, not all studies support its causation of violence [10], and neither does it cause withdrawal effects. It could be still dangerous to drive after marijuana-consumption, but the same for alcohol-consumption. All those confirm that marijuana is far less dangerous than all the other aforementioned drugs. Then let me turn to its comparison with a commonly-consumed substance: alcohol-drink.

\section{Marijuana in the World History}

\section{Marijuana may harm, but perhaps less than Alcohol}

Although studies differ in detailed findings, in overall marijuaua seems less harmful than alcohol-drink. According to Brownstein [11], marijuana and alcohol-drink affect different parts of body. While alcohol-drink affects mainly by taking brain-space needed for respiration, marijuana's main defects are impact on cardiorespiratory organs (e.g. heart) and loss of behavioral balance like aforementioned one-sensory distortion symptom. Besides, however, alcohol-drink causes more problems as follows. First, it is more likely to cause over-consumption, because it begins to affect the body quite after its full digestion; furthermore, desensibilitized by alcohol, the drink might not perceive that she is over-drinking until leading his/her death. In addition, after its absorption into the body, the alcohol interacts with other substances making its final effects unpredictable. For instance, it might be OK to drink alcohol and Redbull separately, but drinking its combined beverage has reported to the death (e.g. Breakfast 2016). 
In contrast, causing arousal rather than desensibilization, the marijuana-taker can instantly notice its impacts on his/her bodyhis/her heart will beat more, and she/he can fully hear and notice it; so, (s)he will stop its over-taking. Furthermore, marijuana does not have interaction effects as alcohol-drink does [11]. Then, the marijuana's only risk is its sensory/perceptual distortion, and the social consequence of its defects seems limited; for example, its taste-distortion hardly threat our daily life, unless the food contains toxic or the person is chef or professional food-taster; in any other case, no serious social problems are expected; of course that does not justify its consumption at workplace, but this will very rarely happen; and the same goes for alcohol. Taken together, unlike LSD and other drugs, marijuana's defects do not reach to unreal delusion or highrisk of over-dosing. In my view, those defects are not enough to say that marijuana is dangerous just like as alcohol-drinking.

Why marijuana is Considered Drug while Alcohol is not? Social Definition Role by Universal Presence and Culturalization

Despite that marijuana harms less than alcohol-drink, it is called 'drug'. And the reason for that is rather socio-historical rather than scientific; unlike marijuana alcohol could not be branded as drug due to its so early-begun universal history. Alcohol-beverage was first made in China at 7000-6650 BC with grapes, hawthorn berries, honey, and rice [12] this history shows alcohol-drink can be made with anything fermentable, and therefore it could have existed from ancient age. Even the first-ever product in China was made with tree branch (hawthorn)! Since it could be made almost with everything, and the alcohol-drink could become a part of the most societies' culture. It is not the same for Marijuana; it is extractable only from cannabis, and its cultivation requires rigorous conditions; for example, about 6.2 liter watering per day, more than 18 hours with light; and most importantly, the humidity $40^{\circ}-60^{\circ}$. Only some parts of the world have such humidity level. Even in the U.S. alone, the temperature ranges from 21ㅇ-9 ${ }^{\text {a }}$ (CityRating.com 2018). This means, only limited parts of world can grow cannabis and produce marijuana. And fortunately or unfortunately, its majority comes from Latin America, neighboring U.S.

\section{Marijuana in US}

\section{Historical Origin: Why only in U.S., Not in Europe?}

Although only 9 out of 51 states (Alaska, California, Colorado, Maine, Massachusetts, Nevada, Oregon, Vermont, and Washington) [13], by 2016 more than half of Americans, reaching to 160 million, have smoked marijuana [14], reaching to 160 million. However, only California meets such needs to produce the majority [15], and national demands are far more than it can produce. Besides, such legalization seems to spread more in close future. Perhaps, we could see some day when marijuana is consumed more than tobacco. And such diffusion is partially attributable to rising social tolerance on marijuana-consumption, beyond legalization/ illegalization. Although this is a recent trend, it is also outcome of the dialectic interaction with the historical origin and facts, and is also product of interaction with U.S. neighboring countries' situation. Then let me elaborate about its historical origin. Before black slaves' immigration, the European-origin immigrants grew hemp.
But unlike other derivatives of cannabis, the hemp has only $1 \%$ of THC (Tetrahydrocannabinol) the main component causing euphoric-high, so its effect could not be the same as that of marijuana. Far later, marijuana could be recognized following inflow of non-white immigrants, for two distinct periods. The first wave was the time for inflow of black slaves; their African ancestors, centuries before Africa's colonization, consumed dabba (what they called marijuana)'s psycho-effects for the recreational and medical use [16]. Its heritage was transmitted to U.S. later. Meanwhile, its second wave was led by inflow of Mexican immigrants, who were fleeing from 1910 Mexican Revolution's disasters.

While tobacco was spread to Europe at earlier time, preventing marijuana's adaption [16], in U.S. it became popular only since the 20th century, quite after adaptation and settlement of marijuana. Until then, tobacco had been used only for economic purpose, like alternative means of transaction to buy indigenous lands [17], or for exporting to Europe [18]. This trend lasted until the 20th century, so until then marijuana could remain as the main consumption item. However, its racial origin it was first introduced by black slaves and Mexican immigrants. Those racial characteristics gave white Americans' fears of marijuana-diffusion, partially due to their intrinsic racism and anti-sentiments. Also for the fear of the situations of having to live with strangers like Mexicans, they fell into false-humors like those Mexican immigrants are violent for consuming marijuana [19]. And that was followed by the wave of marijuana-prohibition across nationwide during 1920s [20].

\section{Late Social Awareness on Racist Origin of Marijuana-Pro- hibition History}

It is only since 2010 s that the racist origin of marijuana-prohibition began to receive social attention and criticism [21]. Such ideological trend sometimes affects social opinion more than scientific findings, generating the moral pressure to follow the wave [22]. Since the anti-racism keep being an important issue in U.S. [23], it makes harder for the conservative to oppose to the legalization of marijuana associated with anti-racism. Although only one tenth of all U.S. states has legalized marijuana until now (five out of 51), according to Salvanto et al. [14], totally more than half of American population (about 1.6 million) have smoked marijuana. Salvanto, et al. [14] however, also pointed out that despite recent sharp increase of marijuaua-smokers, there are few voices warning against legalization and further diffusion. Such anti-marijuana voices can be also suppressed by scientific findings that marijuana defect had been hitherto exaggerated, and also by the conspiracists theory that marijuana-prohibition has serve to the interest of big pharms [24].

All those factors reduce the grounds for any legal control against the marijuana's diffusion. Similarly, even if the legalization phase slows down, the marijuana-consumption will keep increasing. Above all, all the aforementioned elements can make people strongly believe in marijuana's harmlessness, and tempt them to justify their own over-consumption. Such possibility is far from being desirable; although marijuana is less dangerous than other drugs, and although it is hard to over-consume at once, its longterm consumption can still harm and cause social problems. But by now, any prospective social-loss by marijuana's over-diffusion 
in the U.S. is going to be ignored by so-dominant pro-marijuana ideologies and facts. Until here, I discussed the grounds to say why marijuana-consumption will keep diffusing and increasing for a while in the U.S. society. That means also the continuing increase of marijuana demand, which would require the corresponding growth in production. But by now U.S.'s domestic production hardly satisfies such need, and here Latin America's role should be considered. That is what I want to discuss in the next chapter.

\section{Marijuana's Legal Status In Latin America}

I have mentioned that in U.S., only California has suitable natural conditions for cannabis/marijuana plantation. In the past that did not mean marijuana's supply shortage, because also consumption was mostly done in California, about $70 \%$ of total demands in U.S. [25]. But it is no longer the case, being that its consumption is rapidly spreading to Eastern regions like Texas [26]. And California's production is not enough to supply all other states' marijuana demand [27].

\section{Legalization/Allowance of other Latin American Coun- tries than Mexico}

As aforementioned, in U.S., only California has natural conditions for cannabis/marijuana plantation. In the past, its consumption was also concentrated in California, reaching to $70 \%$ of all consumptions nationwide [25]. But now the trend is changed; the consumption flow is rapidly spreading more to Eastern side like Texas. And California alone cannot supply all those wide-spreading demands [27]. Then, where can the rest of consumption be met from? The answer is Latin America and Caribbean countries [28]. That includes not only Mexico with its notorious drug-cartel and neighbor bordering with U.S., but also Colombia, Jamaica, and Paraguay. But among them, only two countries only Mexico and Colombia have enough lands and capital resources to create substantial-size marijuana markets or industries. Neither have the majority of Latin American countries have officially legalized marijuana/ cannabis consumption/possession/selling. For medical purpose, only Colombia, Peru, Chile and Uruguay have legalized it [29], while Mexico is getting close to it after a series of events, for even fewer for legalization of personal use and possession, only Uruguay has done it [29].

In reality, however, it might not be critically relevant whether it is officially legalized or not, except pre-2013 Mexico and current Argentina, where the prohibition rule has real effects. In the other countries, though formally outlawed, police and security authority mostly allow marijuana-smokers, for free or with bribe. In fact, many tourists having travelled to countries like Peru unanimously witness and report that even if it is illegal, the arrest is rare [30]; Donnel [31]; and Twotentwice [32]. In the same context, in Corda and Fusero [33], only Argentina's law turned out effective to control marijuana-consumption.

\section{Mexico: Wind of Liberalization after Long-Term Strict- ness}

According to Corda \& Fusero [33], Mexico's regulation has been relatively strict. Perhaps by influence of seriousness of narcotraffic impacts on society, by 2009 the marijuana control law was drastically reinforced through a reform "small-scale narcotics law (Ley de Narcomenudeo)". This modified law penalizes any of possession/ circulation/trafficking of marijuana/cannabis, as follows:

a. Having less than five-grams cannabis: misdemeanor, ought to pay a fine

b. All of the rest are punished with imprisonment

c. $\quad 5 \mathrm{~g}-5 \mathrm{~kg}$, non-commercial possession:10 months -3 years

d. $\quad 5 \mathrm{~g}-5 \mathrm{~kg}$, possessing for commercial purpose: $3-6$ years

e. Over $5 \mathrm{~kg}$, possessing without alleged trafficking purpose: $4-7$ years

f. Over $5 \mathrm{~kg}$, possessing with alleged trafficking purpose: 5 15 years

g. Arrested after trafficking over $5 \mathrm{~kg}$ : $10-25$ years

And regardless of whether legal punishment was implemented, all those records remain. Besides, the legal authority is entitled to implicate cannabis-users (not only possessors listed above), and also can arrest person when his possession amount does not seem over threshold. This reform with strict penal regulations faced a lot of resistance from social groups, and by 2013 the consumer-group called 'SMART' began to promote petition to re-trial on whether it is constitutional. By 2015 it was sentenced to be 'unconstitutional', leading government to largely mitigate the strictness. And in the same year, a girl of 9 years old with the most-serious epilepsy 'Lennox-Gastaut syndrome", who would die if not treated with cannabis-derived medicines, could receive cannabis-treatment for her father's legal appeals over a year. This event later led to full legalization of medical cannabis in Mexico.

In sum, Mexico's strict rules against cannabis/marijuana was tightened during 2003-2013, but then had to be mitigated by pressures of collective social voice calling for more rights. But even now, unlike many other countries of Latin America, the right for marijuana in Mexico is limited only to medical use.

\section{Expected Marijuana Trade Pattern from Latin America}

With the discussions above, it becomes clear: not only U.S. and Canada, but also Latin America is moving toward allowing marijuana-consumption. Furthermore, whether having legalized or not, mostly marijuana-possession tends to be out of vigilance in Latin America. In such social atmosphere, unless involving drug-cartels, there are enough rooms for unblocked marijuana circulation, with the authority's unawareness or implicit overlook. Another factor for free circulation is that most Latin American governments' lack of ability to effectively coordinate local/provincial/national administration/legal-system and implementations [34]. In short, the loosen legal binds lead to de facto social acceptance of marijuana diffusion, unless it becomes narcotraffic item. Then, what is the most likely process and path of U.S. marijuana's import from Latin America? Furthermore, who are the main actors and winners? The below discuss about those possible scenarios. 


\section{Notorious Mexico Cartel's Role -They will not Sell, but Mediate}

In the previous section, I have confirmed the marijuana-consumption is widely spread in Latin America, beyond its legalization or illegalization. Paradoxically, this discourages Mexico's drug-cartels from getting involved U.S. marijuana trafficking. Because the price cannot be extreme for a good everyone can sell and buy, leaving little rooms for rent-seeking for the part of Mexico cartels seeking for the part of Mexico cartels. This logic can be supported by antecedents of Netherlands [35], in which drug legalization was introduced to reduce drug addiction.

Even so, there are other ways for Mexico cartels to seek profits; that is, high-price renting of their secret trafficking-roads to their complicit officials or business-runners. Here, it should be remembered that Mexico cartel has established a nationwide connection with various regions' officials and business-owners, which have protected them from any legal actions, arrests, and vigilance. While Mexico cartels have little incentives to get involved themselves in U.S. marijuana's trafficking, they could facilitate their conspirators to monopolize or get special merits in marijuana/cannabis export from Colombia to U.S. The key factor for this is the secret-road mentioned just above, which during 1980s and 1990s Mexico cartels developed to transport drugs clandestinely from Colombian drug-gangs' base to U.S., while their colluding Colombian cartels, mainly based on the city Medellin, were mostly disseminated by government armies and special force-team "search bloc (bloque de busqueda, in Spanish) during 2000s [36], the secret road connecting them with Mexico cartels could not be affected; because the roads or underground tunnels were out of Colombian border and therefore out of Colombian government's control. So Mexico drug cartels still face few barriers to rent or use their past roads from Colombia to U.S.

Furthermore, for the Mexican officials/businessmen colluding with drug cartels, it would be more advantageous to take drug-cartels' secret roads instead of using normal infrastructures to transport marijuana/cannabis to U.S. First, Mexican law has legalized the medical use of cannabis/marijuana, but not its transport crossing its territory; the same applies even if the marijuana is legalized and approved one in its origin country like Colombia. Second, most Latin American countries, including Mexico, has very poor infrastructure barring efficient transport of marijuana [37]. While those imply that both law and infrastructure of Mexico are obstacle to marijuana transport from Colombia to U.S., the exclusive access to drug-cartels' secret roads will assure very fast, unchecked and monopolistic business of retailing Colombian marijuana to U.S. In any case, Colombia marijuana will hardly arrive to U.S. market directly without any retailer; because, Colombian government can do little to develop poor infrastructure out of its territory where its marijuana has to pass by for exportation.

\section{Will Central America Keep Cooperating for U.S. Drug?}

Another thing to count is Latin American governments' will to cooperate for drug problems suffered by U.S., not by themselves.
And precedents say it depends on governments' political orientation. That is, the leftist governments are less likely to cooperate for U.S.'s drug-problem for two reasons. First, many of them historically suffered military or economic sanctions by U.S. (e.g. Chile, El Salvador, Nicaragua, etc.) [38]; therefore, simply they cannot be easily good friend with the U.S. Second, at least metaphorically, they basically consider U.S. as the capitalist empire compromising their nations' equality and independence [39]. With those factors of antipathy to U.S., the leftist governments have few reasons to care about problems which are not of their own. Its best example is Nicaragua, currently led by the leftist party Sandinista National Liberation Front, who has a long tradition and has sustained firm popular support over the decade since 2006 election; and previously until 1990, it had to struggle with U.S. supporting its counter-militia called contra, who was fearing socialism-diffusion in Latin America [38]. According to Peralta [40], Nicaragua's antipathy caused by this history still persists. Meanwhile, Peralta also shows there are controversies on whether Nicaragua government is involving in narcotraffic themselves. However, Peralta also assure that at least Nicaragua lacks a deep concern on U.S.'s drug-problem, as implied by officials' quotes "Nicaragua does what it can do [40]". For other Latin American leftist countries, the same goes though differing in the degree. Then, let us see the current ideology map of Latin American governments. With the end of pink tide, it seems as if the whole Latin America were becoming rightist and therefore more willing to cooperate for U.S.'s drug-problems. However, it is true only for South America. In Central America, except only Honduras, the majority is still on the leftist side.

a) Nicaragua: Daniel Ortega, his third term [41]

b) El Salvador: Salvador Sanchez Ceren, formerly leader of guerilla [42]

c) Costa Rica: Guillermo Solis, also leftist [43]

d) Panama: Juan Carlos Varela -he is conservative, but at odds with another conservative-leader Ricardo Martinelli, and he opened the new diplomacy with China $[42,44]$;

e) Mexico: The presidential election is scheduled to August 2018, and Andres Lopez Obrador of leftist side is a strong favorite.

Those examples above confirm that the Central America still is closer to leftist ideology, leaving little room for active cooperation for U.S. drug control. That is added by fact that U.S. drug problem actually costs far more that it sounds at first glance; for instance, detecting those secret paths involves massive costs for tracing underground tunnels and other not-easily-accessible geographical areas [45]. This will, very probably, lead to simply overlooking of marijuana's secret passage through clandestine path into U.S. starting from Colombia and passing by Central America, and Mexico. Taking together, the three facts the expected taking-power by leftist regime not friendly with U.S., the Mexican drug cartels' wide-spread connection with officials/business-owners to make a fortune by getting access to exclusive covert road of drug-trafficking, the legal and 
logistical hardships to transport marijuana by legitimate means affirm that the legally-produced Colombia marijuana is transacted in monopolistic smuggling, at the hand of Mexican retailers who are connected with drug cartels [46-53].

\section{Discussion}

\section{Summary on U.S. Marijuana's Social Features and Pre- dicted Circulation Pattern}

The main messages of the present article can be summarized as follows. In the first part of this article, I discussed the real and perceived nature of marijuana, and its social recognition over time in the U.S. society in relation with scientific findings and racist/anti-racist ideology. In detail, I stated:

a) All drugs along with alcohol and tobaccos harms to the certain degree; what matters are how much more than others. Given that, Marijuana is branded as drug not because of its real health effect, but rather historical and cultural backgrounds.

b) Recent findings disprove that marijuana harms more than alcohol-drinks. Then the reason for considering marijuana drug and not for alcohol-drink is rather historical and cultural ones; only the latter could be the universal culture from ancient age, due to its producibility with any fermentable crop.

c) Since late 2000 s that U.S. scientists found marijuana defects had been exaggerated, and marijuana-legalization gained social voice with spreading recognition about historical racism lying in earlier marijuana-prohibition. SO unrestraint marijuana-consumption and demands are diffusing in U.S., but domestic production cannot keep so large-demand, because natural condition allows only California to produce it. Therefore, import will increase, especially from Latin America.

d) Besides, the second part of the present paper dealt with possible path of industrializing Colombia's marijuana's import to the U.S., mediated by the Mexican retails who are to take advantage of drug cartels' secret roads, which is much more efficient for marijuana's monopolistic circulation. In detail, I stated the follows:

e) First, that soaring import demand is likely to be met mostly by Colombian marijuana's transport by Mexicans who are not drug-cartels themselves but are connected with them.

f) Secondly, Colombia is the most leading country in Latin America, for industrialization of marijuana-production. But their transport technology by public capital does not allow efficient transport. In any case, besides, it has to pass by Mexico, being faster than sea transport.

g) Thirdly, on the other hand, Mexico drug-cartels have their own exclusive drug-route from Colombia to U.S. developed from 1980s, being efficient than transport through formal infrastructure.

h) Fourthly, while they are little likely to get involved in marijuana-trafficking themselves, they could boost their associates' monopolistic retailing by conceding their exclusive covert-path to their connected officials or business-owners.

i) Lastly, to such expected large-influx of marijuana from Latin America, there are few barriers, regardless of whether it is legalized or not by country. Furthermore, current and upcoming governments in Central America including Mexico are likely to be of leftist, leaving few reasons to cooperate for U.S.'s own drug problem.

j) Taking all together, in close future, it is very probable that overflow of marijuana from Colombia to U.S., mediated by monopolized retail of Mexican merchants who have connection with Mexican drug cartels to secure their exclusive access to secret routes of marijuaua-trafficking developed by those cartels.

\section{Implication}

Until here, I have assured that marijuana is more considered to be drug than alcohol-drink not based on scientific evidence, but due to various historical and geographic factors which bared earlier and broader culturalization of marijuana-consumption. However, the current social opinion in U.S., conversely, is becoming too favorable to marijuana-consumption. Although marijuana turned out less dangerous than alcohol-drink, its long-term consumption still can damage individuals and societies. Simply speaking, going too-far can be problematic. And by now, paradoxically, because of the late reflection on past racist roots of earlier marijuana-prohibition, could make any attempt to control marijuana-consumption as racist sin. The recognition of the wrong past could result in going wrong again, this time in opposite direction. Very often, the moral wins over facts and logics. Here is its familiar example: politics, where ideological metaphor often defeats politicians' real will and abilities. In this sense, emphasizing past racist root can discourage any alert, criticism, or regulation against marijuana abuse; nobody wants to hear he/she is racist. It is so especially for U.S., where the anti-racism keeps being of top-priority issue.

In turn, with Latin American governments' lack of motivation to cooperate for U.S.'s marijuana control, it would be only U.S. government itself who has to control and manage marijuana's overflow-problem by import from Colombia to Mexico, or any other countries. Furthermore, the U.S.'s authority, could find it uncertain about when to get more involved with marijuana-circulation from Latin America. In any case, they will face soon the need of expanding their vigilance and attention beyond Mexico cartels, to broader areas in Mexico and other countries.

\section{Significance of the Present Study, and Future Research}

This study's aims and elaborations differ from most articles on marijuana; rather than specific contexts of effects of it, I contemplated both scientific, historical perspectives on marijuana's social consideration on drug, and its social meaning's change over time in U.S. society, and the role of U.S. relation and current drug/marijuana situation of Latin American countries. Summing up the findings and trends drawn from those distinct types of researches involving marijuana, I could conclude with prediction and suggestion on ex- 
pected marijuana flow from Latin America to U.S. By doing so, this paper reveals the importance of taking into account the social contexts including ideological games, as well as interaction between domestic movements and international trends (e.g. Latin American leftists' cooperation for U.S. drug).

Simply speaking, I showed how the current U.S. marijuana issue should be analyzed with account of both American history and ideological changes, and also its neighboring Latin America's situation for the latter, the examples include not only that on marijuana allowance/legalization but also other factors like infrastructure, social corruption influencing drug-cartels' role, and the heritage of past drug wars. And I am aware that the elaborations in these papers were not largely based on the grand-theories, but rather comprehending a variety of facts and small findings. However, this does not necessarily lower the value of the present study. Rather, that could be understood as that drug-consumption issue varies over time, as outcome of interaction of various factors at that time (not permanent ones).

The major limitation of this study is, I could have made further clarification about actors and figures; for instance, which province's drug cartels in Mexico could make retailing network for marijuana? And how much can Colombian industrial marijuana cover the supply shortage in U.S.? Unfortunately, to address those questions, in need of concrete number data to answer, we should wait to observe a bit more about the ongoing trend. Because both the new source of supply industrialized Colombian marijuana, and spread of marijuana-consumption into the Eastern regions of U.S., still have short history having begun since mid-2010s. So upon additional observation of upcoming trend and the degree of trend consistency, for only one or two years, we could say more exactly about the degree of role of Colombian marijuana-industrialization, and degree of role by Mexico drug-cartels' affiliates, in prospective U.S. marijuana supply. I believe the both will make influence on U.S. marijuaua supply to a certain degree, but I cannot say to which degree, exactly. In close future, further studies would be needed for such precisions in predicting U.S. marijuana's inside and outside flows, in order to draw appropriate policies and measures.

\section{References}

1. Dochuk, Darren (2010) From Bible Belt to Sunbelt: Plain-Folk Religion, Grassroots Politics, and the Rise of Evangelical Conservatism. WW Norton \& Company.

2. Klein Joe (2016) Don't Believe the New Myths About America's White Working Class. Time.

3. Frank Richard G, Harold A Pollack (2017) Addressing the Fentanyl Threat to Public Health. The New England Journal of Medicine 376 (7): 605-607.

4. L Henderson Gary (1991) Fentanyl-Related Deaths: Demographics, Circumstances, and Toxicology of 112 Cases. Journal of Forensic Sciences 36: 422-433.

5. American Addiction Centers (2017) Heroin Withdrawal Timeline, Symptoms and Treatment. American Addiction Centers 888: 1-6.

6. Yudofsky, Stuart, Jonathan Silver, Robert Hales (1993) Cocaine and Aggressive Behavior: Neurobiological and Clinical Perspectives. Bulletin of the Menninger Clinic 57 (2). Bulletin of the Menninger Clinic: 218226.
7. Rezayof Ameneh, Sara Assadpour, Sakineh Alijanpour (2013) Morphine-Induced Anxiolytic-like Effect in Morphine-Sensitized Mice: Involvement of Ventral Hippocampal Nicotinic Acetylcholine Receptors. Pharmacology Biochemistry and Behavior 103(3): 460-466.

8. Ungerleider JT, DD Fisher (1967) The Problems of LSD-25 and Emotional Disorder. California Medicine 106 (1): 49-55.

9. Zolfagharifard Ellie (2014) Mystery of 'the Munchies' Revealed: Cannabis Use Heightens Sense of Smell and Taste. Daily Mail.

10. Gupta, Sanjay, Stuart Gitlow, Lester Grinspoon, Donald Abrams, et al. (2013) Top 10 Pro \& Con Arguments Should Marijuana Be a Medical Option? PROCON.org.

11. Brownstein, Joe (2014) Marijuana vs. Alcohol: Which Is Really Worse for Your Health? LiveScience.com.

12. Krisinger John (2016) A Look at the History and Science of the Alcoholic Beverage The Alcoholic Beverage History. British Columbia Canada.

13. McVey, Eli (2016) Marijuana Legalization by State, Chart of the Week. Marijuana Business Daily.

14. Salvanto Anthony, Fred Backus, Jennifer De Pinto, Sarah Dutton (2016) Marijuana Use and Support for Legal Marijuana Continue to Climb. CBS News.

15. Mcgreevy Patrick (2017) California Has Too Much Pot, and Growers Won't Be Able to Export the Surplus. Chicago Tribune.

16. Duvall Chris S (2017) Cannabis and Tobacco in Precolonial and Colonial Africa. Oxford Research Encyclopedia of African History p. 1.

17. Routh, Hirak Behari, Kazal Rekha Bhowmik, Jennifer L Lawrence, Charle Parish, et al. (1998) Economic Aspects of Tobacco during the Colonial Period 1612-1776. Clinial in Dermatology 16(5).

18. Sharon Ann Murphy (2017) Early American Colonists Had a Cash Problem. Here's How They Solved It. TIME.

19. McDonald David (2017) The Racist Roots of Marijuana Prohibition. Foundation for Economic Education.

20. Bonnie, Richard J, Charles H Whitebread (2018) Passage of the Uniform Narcotic Drug Act. In The Forbidden Fruit and The Tree of Knowledge: An Inquiry into the Legal History of American Marijuana Prohibition 1927-1937.

21. Pagano Alyssa (2018) The Racist Origins of Marijuana Prohibition. Business Insider.

22. Tom Jacobs (2015) Ideology Often Trumps Science, Especially among Conservatives. Pacific Standard.

23. Ngaruiva Christine (2016) 3 Steps to Combat Racism in America. Time.

24. Koh, Jae-Gu (2017) The Legalization of Medical Marijuana Shakes Position of Large Pharm Companies. Medipharms Today.

25. Grey B (2018) Cannabis: All Bases Covered, California Is About To Bring The 'Green Rush'. IP Analytics.

26. Reeve Elspeth (2013) A Map That Shows the Dramatic Spread of Legal Weed in the U.S. - A Look at the Recent Spread of Liberalized Marijuana Laws across America. The Atlantic Daily.

27. James Rainey (2018) Why California Won't Necessarily Grow (All) America's Marijuana. NBC News.

28. Harkinson Josh, Brett Brownell, Julia Lurie (2014) Mind-Blowing Facts about Marijuana Production in America. Mother Jones.

29. Gonzalez Elizabeth (2017) Weekly Chart: Where Does Latin America Stand on Marijuana Legalization? Americas Society/ Council of the Americas.

30. Kim, Bori (2017) My Opinion about Marihuana Legalization Cons. Tistory. 
31. Donnel Tonny (2017) Is Marijuana Legal in Peru? New Peruvian.

32. Annonymous (2018) The Top 25 Marijuana Destinations in the World. Twotentwice - Information for the High Intent User.

33. Corda Alejandro, Mariano Fusero (2016) Cannabis in Latin America and the Caribbean: From Punishment to Regulation. Drug Policy Briefing 48.

34. Rioja Felix K (2001) Growth, Welfare, and Public Infrastructure: A General Equilibrium Analysis of Latin American Economies. Journal of Economic Development 26 (2): 119-130.

35. Leuw Ed (1991) Drugs and Drug Policy in the Netherlands. Crime and Justice 14 (c): 229-276.

36. Streatfield Dominic (2010) Interview with DEA Agent.

37. Research, BMI (2017) Latin America Infrastructure : Key Themes For 2017.

38. Carothers, Tom H (1991) In the Name of Democracy: US Policy toward Latin America in the Reagan Years. Univ of California Press.

39. Aidi, Hisham (2015) What's Left of the Latin American Left? Al Jazeera.

40. Peralta Eyder (2014) Nicaragua Follows Its Own Path In Dealing With Drug Traffickers. NPR - Politics and Policy p. 1-18.

41. Agency, Reuters (2016) Nicaragua Leader Daniel Ortega Wins Third Consecutive Term. BBC.

42. Ceja, Luchos Granados (2015) El Salvador's Guerrilla President Marks 1 Year in Office. Tele Sur English.

43. Kane Corey (2014) Live Costa Rica Presidential Election Results. The Tico Times.

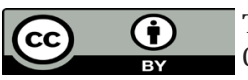

This work is licensed under Creative Commons Attribution 4.0 License

Submission Link: https://biomedres.us/submit-manuscript.php
44. Winner Don (2011) Martinelli Blames Varela For Hurtado Asylum, Calls Him A Liar. Panama-Guide.

45. Paris AFP correspondents in (2009) LSD Reveals Schizophrenia Treatment. AFP.

46. Agency, TRT world (2017) Panama Breaks Ties with Taiwan for 'One China' Policy.

47. Bender, Lauretta, Leonard Cobrinik, Gloria Faretra, DV Siva Sankar (1966) The Treatment of Childhood Schizophrenia with LSD and UML. Biological Treatment of Mental Illness, Proceedings II of the International Conference of the Manfred Sakel Foundation 2(4): 463-491.

48. Bolton WB (1961) Schizophrenia Produced by LSD-25. Occupational Therapy: The Official Journal of the Association of Occupational Therapists 24(5): 20-23.

49. Costa, Sergio, Francesc Badia (2018) Persistent Inequality: Disputing the Legacy of the Pink Tide in Latin America. Open Democracy.

50. Fisher Gary (1997) Treatment of Childhood Schizophrenia Utilizing LSD and Psilocybin. MAPS Newsletter 7(3): 18-25.

51. G Sedman, Kenna JC (1965) The Use of Lsd-25 As a Diagnostic Aid in Doubtful Cases of Schizophrenia. The British Journal of Psychiatry: The Journal of Mental Science 111: 96-100.

52. Jobs Steve (2018) 'Taking LSD Was a Profound Experience. Good Read.

53. Llewellyn Bigelow, E Terry Goldberg, David G, Joel E Kleinman, Daniel R Weinberger (1990) Ventricular to Brain Ratio and Blink Rate Changes Predict Clinical Response to Acute Amphetamine Challenge in Schizophrenia. Biological Psychiatry 27(9): 97.

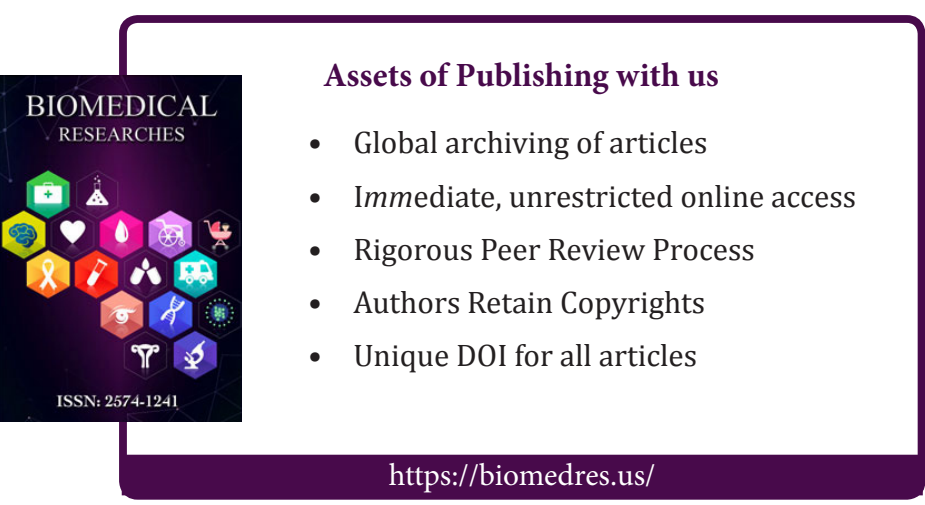

